\title{
MARCADORES DE PATOGENICIDADE EM Yersinia enterocolitica 0:3 ISOLADAS DE SUÍNOS DO RIO DE JANEIRO ${ }^{1}$
}

\author{
Tereza C. A. Leal ${ }^{2,3}$, Nilma C. Leal ${ }^{2}$ e Alzira M. P. Almeida ${ }^{2,4}$
}

\begin{abstract}
Leal T.C.A., Leal N.C. \& Almeida A.M.P. 1997. [Genetic markers of pathogenicity in Yersinia enterocolitica 0:3 isolated from healthy pigs from Rio de Janeiro.] Marcadores de patogenicidade em Yersinia enterocolitica 0:3 isoladas de suínos do Rio de Janeiro. Pesquisa Veterinária Brasileira 17(1):19-24. Depto Microbiologia, CPqAM-FIOCRUZ-MS, Cx. Postal 7472, Cidade Universitária, Recife, PE 50670-420, Brazil.

Sixteen Yersinia enterocolitica serotype 0:3 strains, isolated from pigs from Rio de Janeiro, have been analyzed for genetic and phenotypic markers of pathogenicity. It was observed that only 6 strains harbored the pYV $(+70 \mathrm{~kb})$ plasmid and one strain harbored a small cryptic plasmid of about $8.6 \mathrm{~kb}$. Accordingly only strains harboring pYV were calcium dependent in the MOX medium at $37^{\circ} \mathrm{C}$. Twelve strains showed pesticin sensitivity and the esculin reaction was negative in 13 strains. PCR analysis of pathogenicity genes using specific primers showed the presence of the ail gene in 14 strains, the irp2 gene in one and the $p s a A$ in none. Most of the strains were resistant to ampicillin and carbenicillin, although they were susceptible to sulfazotrin and cefoxitin. For chloramphenicol, tetracycline, kanamycin, gentamicin and nalidixic acid the results varied among the strains.
\end{abstract}

INDEX TERMS: Yersinia enterocolitica, swine, genetic markers, pathogenicity.

SINOPSE.- Foi realizada a caracterização genotípica e fenotípica de fatores de patogenicidade em 16 amostras de Yersinia enterocolitica 0:3 isoladas de suínos sadios do Rio de Janeiro. Foi observado que apenas 6 cepas possuíam o plasmídio de virulência, pYV $(+70 \mathrm{~kb})$ e apresentavam dependência ao cálcio no meio $\mathrm{MOX}$ a $37^{\circ} \mathrm{C}$. Um plasmídio críptico de cerca de 8,6 kb foi encontrado em uma cepa. Doze cepas revelaram sensibilidade à pesticina enquanto que apenas três se revelaram capazes de hidrolisar a esculina. Através de PCR com "primers" específicos, foi constatada a presença dos genes ail em 14 cepas, irp2, em 1 cepa e a ausência de $p s a A$ em todas as cepas analisadas. Quanto aos quimioterápicos, a quase totalidade das cepas mostrou-se ao mes-

\footnotetext{
${ }^{1}$ Aceito para publicação em 12 de novembro de 1996.

Trabalho financiado pela FACEPE (Proc. APQ. 0237-2.12/94).

${ }^{2}$ Departamento de Microbiologia, Centro de Pesquisas Aggeu Magalhães, Fundação Oswaldo Cruz - MS, Campus da UFPE, Caixa Postal 7472, Cidade Universitária, Recife, PE 50670-420.

3 Bolsista da CAPES (Mestrado).

${ }^{4}$ Bolsista do CNPq (Proc. 52.0572-94.7).
}

mo tempo resistente à ampicilina e carbenicilina e sensível ao sulfazotrin e à cefoxitina. As respostas foram variadas frente ao cloranfenicol, tetraciclina, kanamicina, gentamicina e ácido nalidíxo.

TERMOS DE INDEXAÇÃO: Yersinia enterocolitica, suínos, marcadores genéticos, patogenicidade.

\section{INTRODUÇÃO}

Yersinia enterocolitica, bactéria Gram-negativa, da família Enterobacteriaceae, é responsável por diferentes quadros clínicos no homem, que variam de diarréias brandas a adenite mesentérica ou pseudo-apendicite, além de manifestações extra-intestinais (cutâneas, oculares). A espécie é largamente disseminada no ambiente e em diversos animais: répteis, anfíbios, aves e mamíferos. Os suínos são considerados reservatórios, porque os mesmos sorotipos humanos são encontrados na orofaringe e nas fezes desses animais (Bottone 1977). No Brasil, Y. enterocolitica tem sido encontrada no homem, e em animais (cães e suínos), enfermos ou sadios, na água e vários tipos de alimentos (leite, carne e derivados, vegetais) principalmente nos Estados de São Paulo, Rio de 
Janeiro e Rio Grande do Sul (Ceccarelli et al. 1990, Nunes \& Ricciardi 1986, Tassinari et al. 1994, Warnken et al. 1987). As cepas isoladas têm sido estudadas quanto à produção da enterotoxina termoestável (Yst), capacidade invasora "in vivo" através do teste de Sé-reny e "in vitro" em cultura de células Hela. Também têm sido estudadas algumas propriedades relacionadas, ao plasmídio de virulência pYV (Castro et al. 1983, Mendonça et al. 1995, Nunes et al. 1984, Toledo et al. 1982). Entretanto a presença dos fatores genéticos de patogenicidade ainda não haviam sido estudados nas cepas isoladas. Diante disso e considerando que os resultados das provas de fenotipagem dependem da estabilidade dos genes em resposta às variações ambientais (Straley \& Perry 1995) realizamos a caracterização fenotípica e genotípica de alguns fatores de patogenicidade em 16 cepas de $Y$. enterocolitica $0: 3$, isoladas de suínos sadios do Estado do Rio de Janeiro.

\section{MATERIAL E MÉTODOS}

Bactérias e condições de cultivo

Foram analisadas 16 cepas de Yersinia enterocolitica do sorotipo 0:3, isoladas de suínos sadios (língua, amígdalas, linfonodo mesentérico, "swab" retal, conteúdo cecal). Adicio-nalmente foram incluídas quatro cepas isoladas de fezes humanas dos sorotipos $0: 4$; 0:5; 0:6 e 0:13 (Quadro 1). Todas as cepas de Y. enterocolitica foram obtidas da coleção de culturas do Departamento de Bacteriologia do IOC/FIOCRUZ (Rio de Janeiro, RJ). As cepas E. coli ATCC 25922, E. coli R861, Y. pestis EV76, Y. pestis A1122 e Y. pestis P. PB 881, foram utilizadas como controle conforme especificado em cada técnica descrita a seguir. Para os trabalhos, as cepas foram plaqueadas em base de agar sangue (BAB) e crescidas em caldo infuso de cérebro e coração (BHI) durante 18 a $24 \mathrm{~h}$ a $28^{\circ} \mathrm{C}$.

Análise do perfil plasmidial

O DNA plasmidial das 20 cepas foi extraído pela técnica de Birnboim \& Doly (1979) modificada na Escola Paulista de Medicina (São Paulo, SP), submetido à eletroforese em gel de agarose, corado com brometo de etídio $(10 \mathrm{mg} / \mathrm{ml})$ e observado em transiluminador de luz ultravioleta.

Extração do DNA total ou genômico

O DNA das 20 cepas de $Y$. enterocolitica foi extraído segundo protocolo descrito por Maniatis et al (1982). O DNA obtido foi quantificado por comparação, em gel de agarose a $1 \%$, com quantidade conhecida de DNA do fago I clivado pela enzima Hind III.

PCR com "primers" específicos

A presença dos genes ail, irp2 e psaA foi investigada pela técnica de PCR com "primers" dirigidos a sequências publicadas desses genes.

Para amplificação de ail foram usados os "primers":

5'- ATGAAAAAGACATTACTAGCT -3' e

5'- GAATCGATACCCTGCACCAAG -3' desenhados a partir da sequência publicada por Miller et al. (1990).

Para amplificação do gene irp2 foram adotados os primers: 5'-AAGGATTCGCTGTTACCGGAC-3' e

5'-TCGTCGGGCACGTTTCTTC T-3' desenhados a partir da sequência publicada por Guilvoult et al. (1993).

Para o gene estrutural do antígeno pH6, foram usados os "primers":

5'-CATGAAAATGAAATGTTTTGC-3' e

5'-AATACATACTCTTCAACACGC-3' construidos com base na sequência do gene psaA publicada por Lindler \& Tall (1993).
Amplificação

Cada reação foi preparada em um volume total de $25 \mathrm{ml}$ por tubo. Cada mistura compreendia: 20 ng do DNA genômico, $1 \mathrm{U}$ da enzima Taq polimerase (CENBIOT/RS), 0,16 $\mathrm{mM}$ de cada desoxinucleotídeo trifosfato (dNTP), 1,5 mM de $\mathrm{MgCl}_{2}, 20$ pmol de cada "primer", $50 \mathrm{mM}$ de $\mathrm{KCl}$ e $10 \mathrm{mM}$ de tris- $\mathrm{HCl}$. As amplificações foram realizadas em um termociclador (Perkin Elmer), programado para 25 ciclos, iniciando por uma etapa de desnaturação de $1 \mathrm{~min}$ a $94^{\circ} \mathrm{C}$, seguida de uma etapa de anelamento de $2 \mathrm{~min}$ a $50^{\circ} \mathrm{C}$, uma de alongamento de $3 \mathrm{~min}$ a $72^{\circ} \mathrm{C}$, e terminando por uma etapa de alongamento final de $7 \mathrm{~min}$ a $72^{\circ} \mathrm{C}$. Os produtos da amplificação foram submetidos à eletroforese em gel de agarose a $1 \%$, em tampão Tris-borato e voltagem constante de $100 \mathrm{~V}$, seguido de coloração com brometo de etídio e visualização em transiluminador de UV. Em cada partida de amplificação, foi incluído um controle negativo, que consistia de um tubo contendo todos os componentes da mistura de reação ao qual não se adicionava DNA e um controle positivo, com o DNA de uma cepa de referência.

\section{Dependência ao cálcio}

Cada cepa foi semeada em duas placas do meio agar oxalato de magnésio (MOX) e incubadas respectivamente a $28^{\circ} \mathrm{C}$ e $37^{\circ} \mathrm{C}$ para comparação do crescimento nas duas temperaturas. $\mathrm{O}$ crescimento das culturas dependentes do cálcio é inibido a $37^{\circ} \mathrm{C}$, enquanto que as culturas independentes do cálcio se desenvolvem de maneira semelhante nas duas temperaturas (Gemski et al. 1980).

\section{Receptor para pesticina}

A sensibilidade à pesticina foi averiguada pela técnica de difusão em dupla camada de agar (Beesley \& Surgalla 1970). A cepa Yersinia pestis EV76 foi usada como produtora de pesticina. A sensibilidade à bacteriocina é evidenciada pelo aparecimento de um halo de inibição em torno das colônias da cepa produtora.

\section{Hidrólise da esculina}

As cepas foram plaqueadas no meio agar desoxicolato com $0,2 \%$ de esculina, conforme descrito por Hofer et al. (1979). As cepas esculina positivas formam colônias negras no meio de cultura e as esculina negativas formam colônias claras.

\section{Antibiograma}

A sensibilidade aos quimioterápicos foi avaliada pelo método de difusão de discos (Bauer et al. 1966) utilizando-se o agar MuellerHilton e os seguintes agentes antibacterianos nas concentrações especificadas: cloranfenicol $(30 \mathrm{mcg})$, ampicilina $(10 \mathrm{mcg})$, sulfazotrin (25 mcg), tetraciclina $(30 \mathrm{mcg})$, kanamicina $(30 \mathrm{mcg})$, cefoxitina (30 mcg), gentamicina (100 mcg), carbenicilina (100 mcg) e ácido nalidíxico $(30 \mathrm{mcg})$. Os discos foram obtidos comercialmente (Biolab, CECON). A cepa de referência Escherichia coli ATCC 25922 foi utilizada como controle.

\section{RESULTADOS E DISCUSSÃO}

Os mecanismos de patogenicidade de Yersinia enterocolitica são complexos e envolvem numerosos fatores. Atualmente vários marcadores de patogenicidade já foram identificados no genoma dessa bactéria. A presença de um plasmídio de cerca de 70 kilobases, denominado pYV, é essencial à virulência das cepas e as culturas que não têm esse plasmídio são avirulentas. $\mathrm{O}$ plasmídio pYV codifica várias proteínas que conferem à $Y$. enterocolitica capacidade de resistir a resposta 
imune primária do hospedeiro (Straley \& Perry 1995). A presença de pYV torna as bactérias dependentes de uma concentração mínima de cálcio de $2,5 \mathrm{mM}$ para crescimento a $37^{\circ} \mathrm{C}$ (Gemski et al. 1980). A análise do perfil plasmidial das 16 amostras de $Y$. enterocolitica do sorotipo $0: 3$ isoladas de suínos sadios do Rio de Janeiro e das 4 cepas humanas dos sorotipos 0:4, 0:5, 0:6 e 0:13 revelou que apenas 6 entre as 16 cepas suínas possuíam o plasmídio pYV (Fig. 1A-E) e que nenhuma cepa humana possuía este plasmídio. A ausência do pYV na maioria das cepas poderia ser atribuída à cura desse plasmídio "in vitro" pelas manipulações no laboratório depois do isolamento. Um plasmídio críptico de cerca de 8,6 kilobases foi encontrado em uma cepa de suíno (Fig. 1D). Todas as cepas analisadas portadoras do pYV, apresentaram dependência ao cálcio no meio $\mathrm{MOX}$ a $37^{\circ} \mathrm{C}$. Tanto as cepas suínas quanto as humanas que não apresentavam o plasmídio, revelaram-se independentes do cálcio, confirmando a ausência do plasmídio. A cepa portadora do pequeno plasmídio também se revelou independente do cálcio (Quadro 1).

Além da presença do pYV, as cepas de $Y$. enterocolitica patogênicas, também possuem fatores de patogenicidade codificados por genes cromossômicos. Miller \& Falkow (1988) demonstraram que a capacidade da $Y$. enterocolitica de aderir e invadir células epiteliais está relacionada à presença de um segmento de DNA cromossômico que foi denominado ail. Foi observado que todas as cepas de $Y$. enterocolitica patogênicas para o homem possuem sequências de DNA homólogas à ail, enquanto que as cepas de origem ambiental, avirulentas, não possuem esta sequência (Miller et al. 1989). Através da técnica de PCR foi constatada a amplificação de um segmento correspondente à ail, a partir do DNA de 14 cepas suínas. Entre as cepas humanas foi observada amplificação de ail a partir do DNA das cepas dos sorotipos 0:6 e 0:13 enquanto que com o DNA das cepas dos sorotipos 0:4 e 0:5 não houve amplificação (Quadro 1). A Figura 2A mostra os produtos da amplificação por PCR do gene ail em 8 cepas suínas e 1 humana.

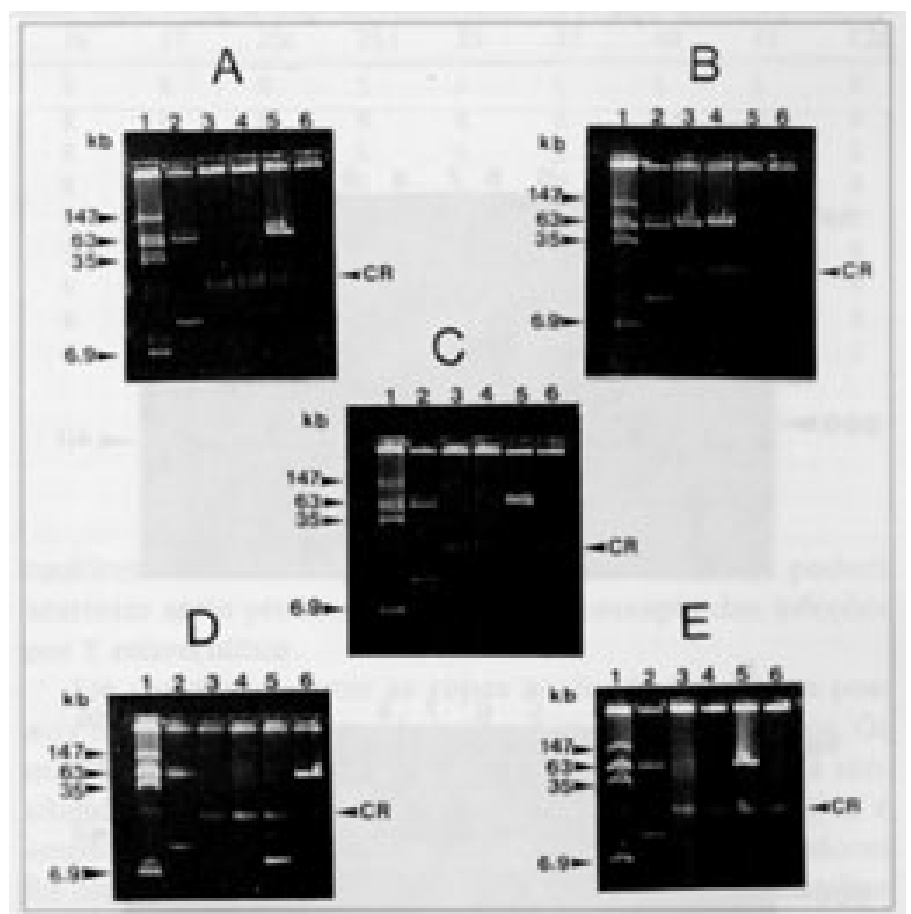

Fig. 1. Perfil plasmidial das 20 cepas (suínas e humanas) de Yersinia enterocolitica, em gel de agarose $0,6 \%$. Linhas, 1: Escherichia coli R861, 2: Y. pestis EV 76. (A) Linhas, 3: Ye 6, 4: Ye 10, 5: Ye 25 c e 6: Ye 14. (B) Linhas, 3: Ye 25 1, 4: Ye 35, 5: Ye 16 e 6: Ye 17. (C) Linhas, 3: Ye f 28, 4: Ye 2, 5: Ye 37 e 6: Ye 184 p. (D) Linhas, 3: Ye 1, 4: Ye 43 p, 5:Ye 5 a e 6:Ye 40. (E) Linhas, 3: Ye 102 p, 4: Ye 5, 5: Ye 41, 6: Ye 124 p.

Quadro 1. Características genotípicas e fenotípicas das amostras de Yersinia enterocolitica

\begin{tabular}{|c|c|c|c|c|c|c|c|c|c|}
\hline \multirow[t]{2}{*}{ Cepas } & \multirow[t]{2}{*}{ Sorotipo } & \multirow[t]{2}{*}{ Origem } & \multirow{2}{*}{$\begin{array}{c}\text { Plasmídio } \\
\text { (kb) }\end{array}$} & \multirow{2}{*}{$\begin{array}{l}\text { Dependência } \\
\text { ao cálcio }\end{array}$} & \multirow{2}{*}{$\begin{array}{c}\text { Receptor para } \\
\text { pesticina }\end{array}$} & \multirow{2}{*}{$\begin{array}{l}\text { Hidrólise da } \\
\text { esculina }\end{array}$} & \multicolumn{3}{|c|}{ PCR } \\
\hline & & & & & & & ail & irp2 & $p s a A$ \\
\hline 6 & $0: 3$ & Suíno & - & - & + & - & + & - & - \\
\hline 10 & $0: 3$ & Suíno & - & - & - & - & + & - & - \\
\hline 14 & $0: 3$ & Suíno & - & - & + & - & + & - & - \\
\hline 16 & $\mathrm{O} 3$ & Suíno & - & - & - & - & + & - & - \\
\hline 17 & $0: 3$ & Suíno & - & - & + & - & + & - & - \\
\hline $25 \mathrm{c}$ & $0: 3$ & Suíno & 70 & + & + & - & + & - & - \\
\hline 251 & $0: 3$ & Suíno & 70 & + & + & - & - & - & - \\
\hline 35 & $0: 3$ & Suíno & 70 & + & + & - & + & - & - \\
\hline 37 & $0: 3$ & Suíno & 70 & + & - & - & + & - & - \\
\hline 40 & $0: 3$ & Suíno & 70 & + & + & - & + & - & - \\
\hline 41 & $0: 3$ & Suíno & 70 & + & + & - & - & + & - \\
\hline 1 & $0: 3$ & Suíno & - & - & + & - & + & - & - \\
\hline 2 & $0: 3$ & Suíno & - & - & + & - & + & - & - \\
\hline 5 & $0: 3$ & Suíno & - & - & - & - & + & - & - \\
\hline 5 a & $0: 3$ & Suíno & 8,6 & - & + & + & + & - & - \\
\hline f 28 & $0: 3$ & Suíno & - & - & + & - & + & - & - \\
\hline $43 p$ & $0: 6$ & Humano & - & - & + & - & + & - & - \\
\hline $102 p$ & $0: 5$ & Humano & - & - & + & + & - & - & - \\
\hline $124 \mathrm{p}$ & $0: 4$ & Humano & - & - & + & - & - & - & - \\
\hline $184 \mathrm{p}$ & $0: 13$ & Humano & - & - & - & + & + & - & - \\
\hline
\end{tabular}


Carniel et al. (1989) observaram que na ausência de ferro, as yersínias patogênicas sintetizam proteínas de alto peso molecular, uma das quais, HMWP2 é codificada pelo gene cromossômico irp2. Foi demonstrado que o gene irp2 está

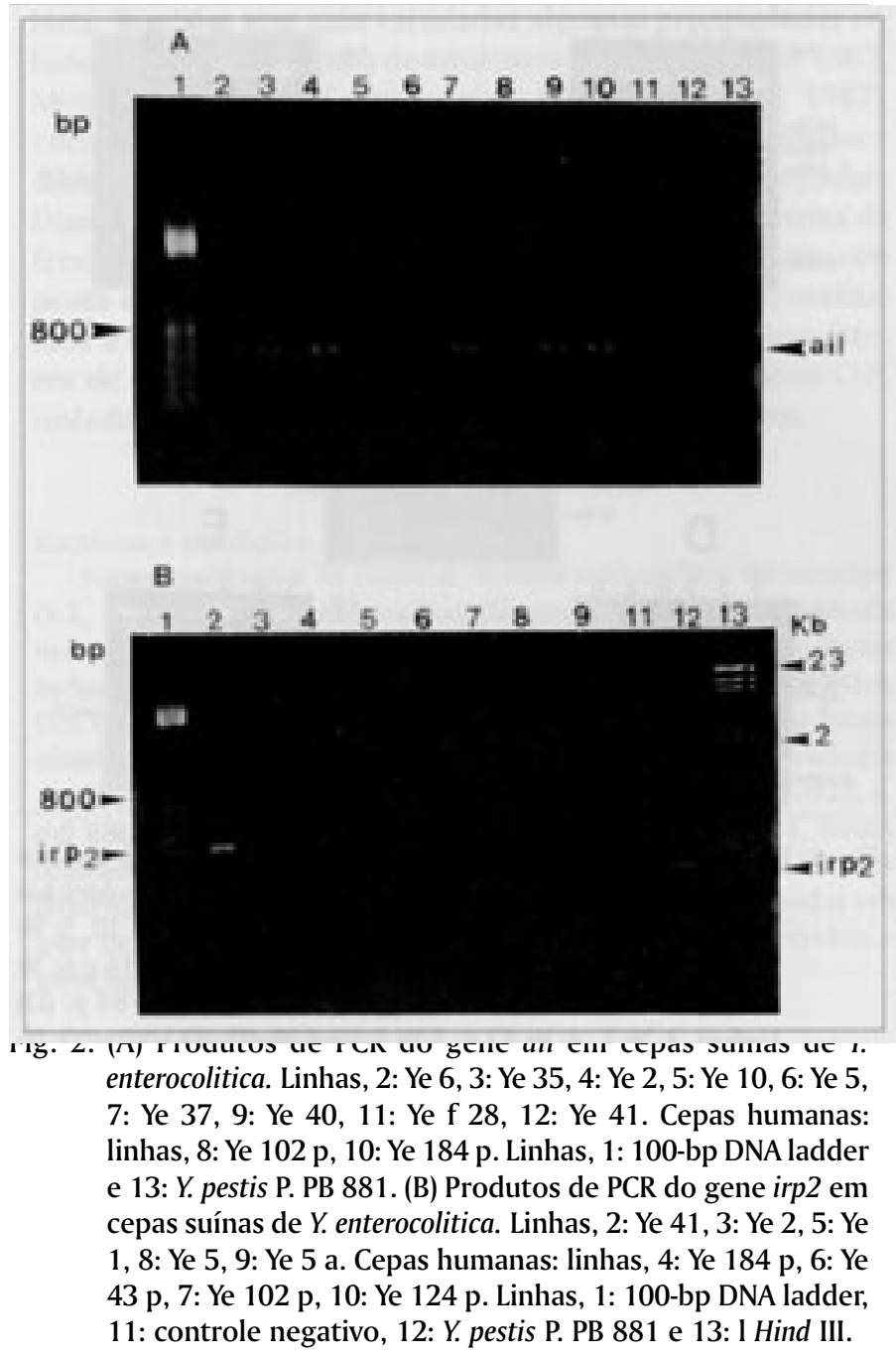

presente apenas nas cepas patogênicas e não se encontra nas cepas não patogênicas (Almeida et al. 1993). Diante desses resultados o gene irp2 é considerado um marcador de alta patogenicidade (Carniel et al. 1992). Entre as cepas de $Y$. enterocolitica analisadas a amplificação do segmento de DNA correspondente ao gene irp2 foi observada apenas na cepa Ye 41 (isolada de suíno). Vale salientar que o tamanho do fragmento amplificado nessa cepa é diferente do fragmento amplificado na cepa de Yersinia pestis P. PB 881 utilizada como controle (Fig. 2B). Este resultado reflete o polimorfismo do segmento de DNA cromossômico contendo o gene irp2 nas três espécies de yersínia patogênicas. Através de hibridização com uma sonda do gene irp2, o fragmento de DNA reconhecido no cromossomo de $Y$. pestis é similar ao de Yersinia pseudotuberculosis porém é diferente do que é reconhecido no cromossomo de $Y$. enterocolitica (Almeida et al. 1993). Não houve amplificação de irp2 nas outras 15 cepas de suínos nem nas cepas de origem humana (Quadro 1).

A capacidade de sintetizar o antígeno $\mathrm{pH} 6$ codificado pelo gene cromossômico $p s a A$ é considerada necessária à virulência da $Y$. pestis. Este antígeno é também produzido por $Y$. pseudotuberculosis que é enteropatogênica (Lindler \& Tall 1993). Entretanto, a presença do gene no cromossomo de $Y$. enterocolitica e a função desse antígeno na patogenicidade dessa bactéria ainda não estão demonstrados. A existência do gene estrutural do antígeno pH6 ( $p s a A$ ) foi investigada pela técnica de PCR, com "primers" específicos desenhados com base na sequência publicada do gene psaA (Lindler \& Tall 1993). Em nenhuma das cepas humanas ou suínas analisadas foi observada amplificação sugerindo a ausência desse gene, no genoma de $Y$. enterocolitica (Quadro 1). A ausência do gene psaA não foi surpreendente porque sua presença em $Y$. enterocolitica jamais havia sido relatada. É provável que este gene seja realmente específico das outras duas yersínias patogênicas $Y$. pestis e $Y$. pseudotuberculosis e não exista em $Y$. enterocolitica.

Foi demonstrado que as cepas de $Y$. enterocolitica patogênicas são capazes de produzir um sideróforo, a yersiniabactina (Heeseman et al. 1993). O receptor para a yersiniabactina (FyuA) é também receptor para a pesticina (Rakin et al. 1994).

Quadro 2. Efeito dos agentes antimicrobianos em cepas suínas e humanas de Yersinia enterocolitica

\begin{tabular}{|c|c|c|c|c|c|c|c|c|c|c|c|}
\hline \multirow[t]{2}{*}{ Antibióticos } & \multirow{2}{*}{$\begin{array}{l}\text { Sorotipos } \\
\text { NNo de cepas }^{\circ}\end{array}$} & \multicolumn{2}{|c|}{$\begin{array}{c}0: 3 \\
16 \\
\end{array}$} & \multicolumn{2}{|c|}{$\begin{array}{c}0: 4 \\
1\end{array}$} & \multicolumn{2}{|c|}{$\begin{array}{c}0: 5 \\
1 \\
\end{array}$} & \multicolumn{2}{|c|}{$\begin{array}{c}0: 6 \\
1 \\
\end{array}$} & \multicolumn{2}{|c|}{$\begin{array}{c}0: 13 \\
1 \\
\end{array}$} \\
\hline & & $\mathrm{R}^{\mathrm{a}}$ & $\mathrm{S}$ & $\mathbf{R}$ & $\mathrm{S}$ & $\mathrm{R}$ & $\mathrm{S}$ & $\mathrm{R}$ & $\mathrm{S}$ & $\mathbf{R}$ & $\mathrm{S}$ \\
\hline Cloranfenicol & & 7 & 9 & 0 & 1 & 0 & 1 & 0 & 1 & 1 & 0 \\
\hline Ampicilina & & 15 & 1 & 1 & 0 & 1 & 0 & 1 & 0 & 1 & 0 \\
\hline Sulfazotrim & & 2 & 14 & 0 & 1 & 0 & 1 & 0 & 1 & 1 & 0 \\
\hline Tetracilina & & 7 & 9 & 0 & 1 & 0 & 1 & 0 & 1 & 1 & 0 \\
\hline Kanamicina & & 9 & 7 & 0 & 1 & 0 & 1 & 0 & 1 & 1 & 0 \\
\hline Cefoxitina & & 2 & 14 & 1 & 0 & 1 & 0 & 1 & 0 & 1 & 0 \\
\hline Carbenicilina & & 15 & 1 & 1 & 0 & 1 & 0 & 1 & 0 & 1 & 0 \\
\hline Gentamicina & & 7 & 9 & 1 & 0 & 1 & 0 & 1 & 0 & 0 & 1 \\
\hline Ácido Nalidíxico & & 11 & 5 & 0 & 1 & 0 & 1 & 0 & 1 & 1 & 0 \\
\hline
\end{tabular}

${ }^{a} \mathrm{R}=$ resistente, $\mathrm{S}=$ sensível 
Quadro 3. Efeito dos agentes antimicrobianos em amostras de Y. enterocolitica do sorotipo O:3, isoladas de suínos sadios do Rio de Janeiro

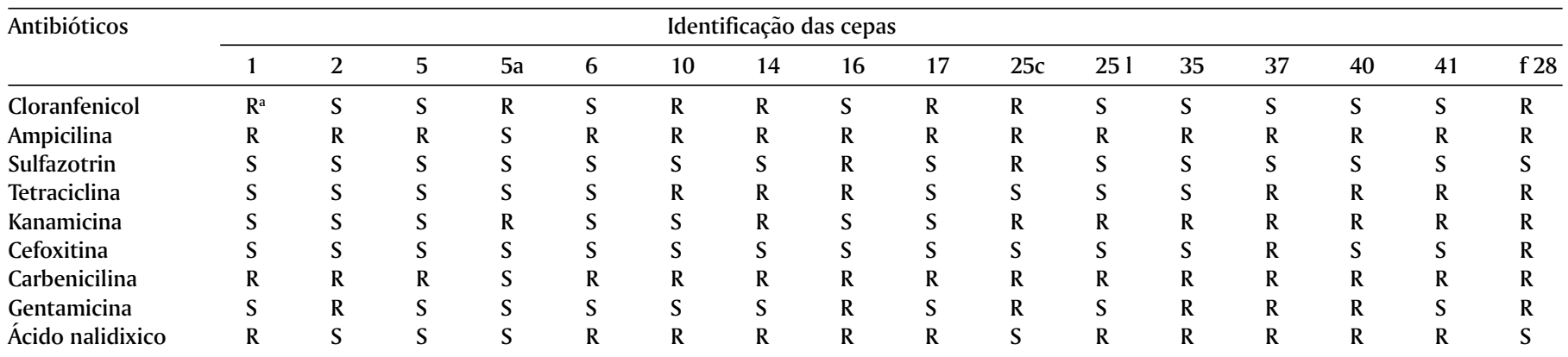

${ }^{\mathrm{a}} \mathrm{R}=$ resistente, $\mathrm{S}=$ sensível.

A pesticina é uma bacteriocina produzida por $Y$. pestis, agente causador da peste (Hertman \& Ben-Gurion 1958). A síntese desta bacteriocina é codificada pelo gene pst localizado em um pequeno plasmídio (pPst) de cerca de 9,5 kilobases, específico de $Y$. pestis (Sodeinde \& Goguen 1988). A sensibilidade à pesticina pode ser considerada um marcador de patogenicidade porque a perda do segmento de DNA cromossômico que codifica a proteina FyuA é acompanhada pela diminuição da virulência das cepas (Heeseman et al. 1993). Doze cepas suínas e três cepas humanas (0:4, 0:5 e 0:6) revelaram sensibilidade à pesticina podendo ser consideradas potencialmente patogênicas, enquanto que a cepa humana, do sorotipo $0: 13$, revelou-se resistente à essa bacteriocina (Quadro 1).

Além dessas e outras características, a hidrólise da esculina é um critério importante na diferenciação fenotípica entre cepas patogênicas (esculina negativa) e não patogênicas (esculina positiva) (Bottone 1977). Através das análises realizadas no presente trabalho a maioria das cepas suínas revelou-se esculina negativa sendo consideradas potencialmente patogênicas e apenas uma era fermentadora de esculina e provavelmente não é patogênica. Entre as cepas humanas, duas foram esculina positiva e duas esculina negativa (Quadro 1).

Nas provas de sensibilidade aos quimioterápicos, a quase totalidade das cepas do sorotipo 0:3 isoladas de suínos, revelou-se ao mesmo tempo resistente à ampicilina $\mathrm{e}$ carbenicilina e sensíveis ao sulfazotrin e cefoxitina e foi observado que as respostas foram variadas frente ao cloranfenicol, tetraciclina, kanamicina, gentamicina e ácido nalidíxo (Quadros 2 e 3). Quanto às cepas humanas estudadas, as amostras dos sorotipos 0:4, 0:5 e 0:6, mostraram perfis de sensibilidade idênticos, porém, diferente do que foi observado com a outra cepa humana $(0: 13)$ que mostrou resistência a quase todos os antibióticos testados, com exceção da gentamicina. Vale salientar que os perfis de sensibilidade aos quimio-terápicos das cepas suínas foram diferentes do das cepas humanas exceto quanto à ampicilina e carbenicila (todas resistentes) e sulfazotrim e cefoxitina (todas sensíveis) (Quadros 2 e 3). A disseminação de cepas dotadas de multiresis-tência aos quimioterápicos como a 184p, poderá acarretar sério problema para a antibioterapia das infeções por $Y$. enterocolitica.

Em conclusão, entre as cepas analisadas nenhuma possuía todos os marcadores de patogenicidade pesquisados. Os marcadores mais frequentemente encontrados foram a sensibilidade para a pesticina, reação da esculina negativa e amplificação do gene ail. A presença desses três marcadores foi observada em $50 \%$ das cepas suínas, a reação da esculina negativa e amplificação de ail em $25 \%$ das cepas, a sensibilidade à pesticina e reação da esculina negativa em $16,5 \%$ das cepas e a sensibilidade à pesticina e amplificação de ail em $8,5 \%$ das cepas. A cepa Ye 41 isolada de suíno sadio apresentou a maioria dos marcadores de patogenicidade pesquisados: presença do plasmídio de virulência, dependência ao cálcio, receptor para pesticina, reação da esculina negativa, além da presença do gene irp2 marcador do fenotipo altamente patogênico. Portanto esta cepa pode ser considerada altamente patogênica e sua disseminação no meio ambiente através das fezes dos animais infectados poderá acarretar sérios problemas para o futuro. Esta cepa, embora pertencente ao mesmo bio/soro/fagotipo (4/O:3/VIII) das outras 15 amostras de $Y$. enterocolitica isoladas de suínos sadios, foi a única que apresentou um perfil genotípico diferente das demais, em um estudo de tipagem pela técnica RAPD-PCR (resultados a serem apresentados em outro trabalho).

Quanto às cepas humanas apenas uma, do sorotipo 0:6 possuía os três marcadores. Na cepa do sorotipo 0:4 foi observado sensibilidade à pesticina e amplificação de ail. Enquanto que as cepas dos sorotipos 0:5 e 0:13 cada uma só possuía um marcador: sensibilidade à pesticina em uma e presença de ail em outra, respectivamente. A ausência da maioria dos marcadores de patogenicidade em três cepas humanas foi surpreendente, uma vez que as mesmas foram isoladas enquanto se procurava identificar agentes patogênicos em fezes de indivíduos enfermos, ao contrário das cepas suínas, que foram isoladas de animais aparentemente sadios. Estes resultados poderiam sugerir instabilidade de alguns segmentos do cromossoma destas bactérias e sua perda, seja pela estocagem prolongada ou pelas manipulações a 
que foram submetidas após o isolamento evidenciam a importância da caracterização fenotípica e genotípica das cepas logo após o isolamento.

Agradecimentos.- Ao Dr. Ernesto Hofer, pelo fornecimento das cepas de Yersinia enterocolitica e à Sra. Yara M. M. Nakasawa, pela assistência técnica.

\section{REFERÊNCIAS}

Almeida A.M.P., Guiyoule A., Guilvout I., Iteman I., Baranton G. \& Carniel E. 1993. Chromosomal irp $^{2}$ gene in Yersinia: distribution, expression, deletion and impact on virulence. Microb. Pathogen. 14:9-21.

Bauer A.W., Kirby W.M.M., Sherris J.C. \& Turck M. 1966. Antibiotic susceptibility testing by a standardized single disk method. Am. J. Clin. Pathol. 45:493496.

Beesley E.D. \& Surgalla M.J. 1970. Pesticinogeny: a characteristic useful for presumptive identification and isolation of Pasteurella pestis. Appl. Microbiol. 19:915-918.

Birnboim H.C. \& Doly J. 1979. A rapid alkaline extraction procedure for screening recombinant plasmid DNA. Nuc. Ac. Res. 7:1513-1523.

Bottone E.J. 1977. Yersinia enterocolitica: a panoramic view of a charismatic microorganism. Crit. Rev. Microbiol. 5:211-241.

Carniel E., Mercereau-Puijalon O. \& Bonnefoy S. 1989. The gene coding for the 190000 dalton iron regulated protein of Yersinia species is present only in the highly pathogenic species. Infect. Immun. 57:1211-1217.

Carniel E., Guiyule A., Mercereau-Puijalon O. \& Mollaret H.H. 1991. Chromosomal marker for the "high pathogenicity" phenotype in Yersinia. Contrib. Microbiol. Immunol. 12:192-197.

Castro A.F.P., Ricci L.C., Almeida A.C.P. \& Oliveira M.S. 1983. Virulence factors of Yersinia enterocolitica isolated from pigs. Revta Microbiol., São Paulo, 14:48-54.

Ceccarelli V.R.S.M., Schmidt C. \& Trabulsi L.R. 1990. Isolamento de Yersinia enterocolitica em um laboratório da cidade de São Paulo. Revta Microbiol., São Paulo, 21:364-365.

Gemski P., Lazere J.R. \& Casey T. 1980. Plasmid associated with pathogenicity and calcium dependency of Yersinia enterocolitica. Infect. Immun. 27:682685 .

Guilvout I., Mercereau-Puijalon O., Bonnefoy S., Pugsley A.P. \& Carniel E. 1993. High-molecular-weight protein 2 of Yersinia enterocolitica is homologous to AngR of vibrio anguillarum and belong to a family of proteins involved in nonribosomal peptide synthesis. J. Bacteriol. 175:5488-5504.

Heeseman J., Hantke T., Vocke E., Saken A., Rakin I., Stojiljkovic I. \& Berner R. 1993. Virulence of Yersinia enterocolitica is closely associated with siderophore production, expression of an iron-repressible outer membrane protein of 65,000 Da and pesticin sensitivity. Mol. Microbiol. 8:397-408.
Hertman I. \& Ben-Gurion R. 1958. A study of pesticin biosynthesis. J. Gen. Microbiol. 21:135-143.

Hofer E., Fernandes M.F.T., Veiga T., Oliveira M.S. \& Abraham A.M. 1979. Isolamento de $Y$. pseudotuberculosis e $Y$. enterocolitica de roedores capturados no município de Friburgo, RJ. X Congr. Bras. Microbiologia, Rio de Janeiro.

Lindler L.E \& Tall B.D. 1993. Yersinia pestis pH6 antigen forms fimbriae and is induced by intracellular association with macrophages. Mol. Microbiol. 8:311-324.

Maniatis T., Frisch E.F. \& Sambrook J. 1982. Molecular cloning: a laboratory Manual. Cold Spring Harbor Laboratory, Cold Spring Harbor, NY, p. 368369.

Mendonça C.L., Lázaro N.S., Duque V.M. \& Hofer E. 1995. Fatores de virulência em Yersinia enterocolitica 0:3 isoladas de suínos sadios, Rio de Janeiro. Pesq. Vet. Bras. 15(1):11-14.

Miller V.L. \& Falkow S. 1988. Evidence for two genetic loci in Yersinia enterocolitica that can promote invasion of epithelial cells. Infect. Immun. 56:1242-1248.

Miller V.L., Farmer III J.J., Hill W.E. \& Falkow S. 1989. The ail locus is found uniquely in Yersinia enterocolitica serotypes commonly associated with disease. Infect. Immun. 57:121-131.

Miller V.L., Bliska J.B. \& Falkow S. 1990. Nucleotide sequence of the Yersinia enterocolitica ail gene and characterization of the Ail protein product. J. Bacteriol. 172:1062-1069.

Nunes M.P., Toledo M.R.F. \& Ricciardi I.D. 1984. Invasibilidade e enterotoxigenicidade de Yersinia enterocolitica e das espécies atípicas de Yersinia isoladas do homem e de cães no Brasil. Revta Microbiol., São Paulo, 15:222-226.

Nunes, P.M., Ricciardi, I.D. 1986. Yersinia enterocolitica: isolamento concomitante de fezes de humanos e cão. Revta Microbiol., São Paulo, 17:220-224.

Rakin A., Saken E., Harmsen D. \& Heeseman J. 1994. The pesticin receptor of Yersinia enterocolitica: a novel virulence factor with dual function. Mol. Microbiol. 13:253-263.

Sodeinde O.A. \& Goguen J.D. 1988. Genetic analysis of the 9,5-kilobase virulence plasmid of Yersinia pestis. Infect. Immun. 56:2743-2748.

Straley S.C. \& Perry R.D. 1995. Environmental modulation of gene expression and pathogenesis in Yersinia. Trends Microbiol. 3:310-318.

Tassinari A.D, Franco B.D.G.M. \& Landgraf M. 1994. Incidence of Yersinia spp. in food in São Paulo, Brazil. Int. J. Food Microbiol. 21: 263-270.

Toledo M.R.F., Serafim M.B., Horton D.S.P.Q. \& Falcão D.P. 1982. Pesquisa de fatores de virulência em Yersinia enterocolitica. Revta Microbiol., São Paulo, 13:143-150.

Warnken M.B., Nunes M.B. \& Noleto A.L.S. 1987. Incidence of Yersinia in meat samples purchased in Rio de Janeiro, Brazil. J. Food Prot. 50:578-579. 